\title{
Socioeconomic Status and Educational Choice of the Children in Bangladesh
}

\author{
Abul Kalam Azad \\ Assistant Professor of Sociology \\ Department of Sociology, Bangladesh University of Professionals (BUP) \\ Mirpur Cantonment, Dhaka-1216, Bangladesh \\ kalamadd@gmail.com
}

\begin{abstract}
This study aims to predict the educational choice $(E C)$ of children in Bangladesh based on the capital factors of socioeconomic status (CAPSES). For collecting data, the study conducted a survey among the parents selected purposively both from urban and rural areas of Bangladesh. After collecting data, the study used SmartPLS software (Windows Version-3) to analyze both the measurement and structural models. The study findings lead to this proposition that the higher the magnitude of socioeconomic status the parents hold to, the higher the likelihood ratio that they will choose the English medium education for their children and the vice-versa. On the contrary, the lower the magnitude of socioeconomic status the parents hold to, the higher the likelihood ratio that they will choose the madrasa or vocational track of education for their children and vice-versa. Overall, the models have predictive power and relevance $\left(R^{2}=0.684\right.$ for EED model, $R^{2}=0.625$ for GED model, $R^{2}=$ 0.347 for MED model and $R^{2}=0.298$ for VED model).
\end{abstract}

Keyword: Choice of Educational Track; Human Capital; Material Capital; and Social Capital

\section{Introduction}

Education is an indispensable agent of socializing the children in any given society. The children of Bangladesh usually begin their early socialisation through one of the four non-professional education systems: General Education (GED), Madrasa Education (MED), Technical-vocational Education (VED) and English Medium Education (EED). The GEDsystem has three basic areas (science, commerce and arts) and tiers (primary, secondary and tertiary). The MED has major twonisabs: Aliya and Qawmii.In addition, maktabs or forqania madrasas exist in the country to teach the Qaeda (the Arabic alphabet), Aampara, and the Quran. And the Hifzul Quran madrasas train the students to memorize the Quran. The VED system has two tiers: primary and secondary. Finally, the EED is run by both British Council Curriculum and National Curriculum.However, what type of educational track a child needs to choose is one of the core research questions in 'educational sociology'.

Bourdieu, one of the famous French sociologists, while writing about French education system, talks about three kinds of capital: economic, social and cultural (Lata L. N. 2013). Bourdieu (1977) emphasised the effects of cultural capital on the education of children and, in 1984, wrote about its three forms: embodied state of mind and body, institutionalised state and objectified state. The first is acquired from the early childhood, parents and family members or professional teachers. The second form is the educational achievement while the third form include books, paintings and artefacts (Bourdieu 1977). This theory has been applied by many researchers to explain students' choice of college and higher education. However, Oakes and Rossi (2003) postulate that the educational choice of children is not only determined by cultural capital but also the three capital factors of socioeconomic status (CAPSES): human capital (HC), social capital (SC) and material capital (MC). 
Many researchers in the recent years, to explain the educational choice of children, applied Oakes and Rossi's (2003) CAPSES model. Unfortunately, none has conducted research based on CAPSES model to explain the educational choice of children in Bangladesh. The study as an underexplained phenomenonhas enough significance and relevance societally and theoretically as well.So, this is the high time to know if these capital factors are significantly associated with EC of the children in Bangladesh.

\section{Objective of the Research}

The key objective of the research is to predict educational choice (EC) of the children in Bangladesh based on CAPSES factors: HC, SC and MC. To achieve this broad objective, the study has the following specific objectives:

- to explore the socio-demographic characteristics of the respondents;

- to know the socio-economic status of the respondentsbased on their HC, SC and MC; and finally

- to measure the statistical association between the magnitudes of the respondents' $\mathrm{HC}$, $\mathrm{SC}$ and $\mathrm{MC}$, and the EC of their children in the study areas.

\section{Literature Review}

In the global context, there are many studies conducted on the relationship between $\mathrm{HC}, \mathrm{SC}$ and MC, and EC of the children.

\subsection{Human Capital and the Educational Choice}

Carneiro and Heckman (2004) suggest to explain educational choices of the children in terms of parental education raher than parental income. Jaeg (2014) finds educational choice to be associated with the academic ability of children. Lyons, et al. (2003) find that in Ireland, the ability to compete in the education market determines parent's choice of school. To Coons and Sugarman (1978), family's philosophic and religious values matter the educational trackchoice of children.

\subsection{Social Capital and the Educational Choice}

It is worldwide known that social advantage is reproduced from parents to children through education(Blau and Duncan, 1967). Social class also has significant effect on the enrolment of children into different tracks of education, where the socially more advantaged children enrol in academic tracks while the less advantaged children enrol in vocational tracks (Breen and Jonsson, 2000). Social stratification determines educational tracks and educational study fields as well (Davies and Guppy, 1997).

\subsection{Matreial Capital and the Educational Choice}

Since the opening of the market system, the principle of school choice has been being determined by the wealth of parents in stead of meritocracy, what Browne (1997) called"the ideology of parentocracy" (Lauder, 1999: 29). Smith and Noble (1995) foundthat money made parents' ability to provide the costs of books, healthier diets, educational toys, charge for trips, material and equipments. Thus, schools in affluent areas tend to be more successful and attract more pupils more funding. Kingdon and Cassen (2007) found the effects of free school meals, low levels of family employment, single parent families and poor educational 
qualifications of parents on the educational choice. Callender and Jackson (2004) examined the effects of the introduction of tuition fees and replacement of grants and loans where they found the potentiality of some applicants to leave universities. Bowles and Gintis (1976) find education being operated in the interests of those who control the work force-capitalist class. Jonsson et. al. (2009) find the association betweenoccupational specialization and educational field choices.

In Bangladeshi context, no studies have hitherto been conducted on predicting EC of the children based on CAPSES factors. However, it was Lata (2013) who addressed the issue of the students' choice of education. Her study was based on Bourdie's theory of cultural capital. She aimed to understand the students' choice of universities, the likelihood of applying to public and private universities and why university choices differ among academically qualified students. Unfortunately, her study was confined only to test Bourdieu's cultural capital theory.Hence, the study has an endeavour to test CAPSES model in the pitch of educational choice of children in Bangladesh.

\section{Conceptual Framework}

Considering the gap of the existing literature, the study aims to test Oakes and Rossi's (2003) CAPSES model in the pitch of educational choice of children in Bangladesh (Figure 1):

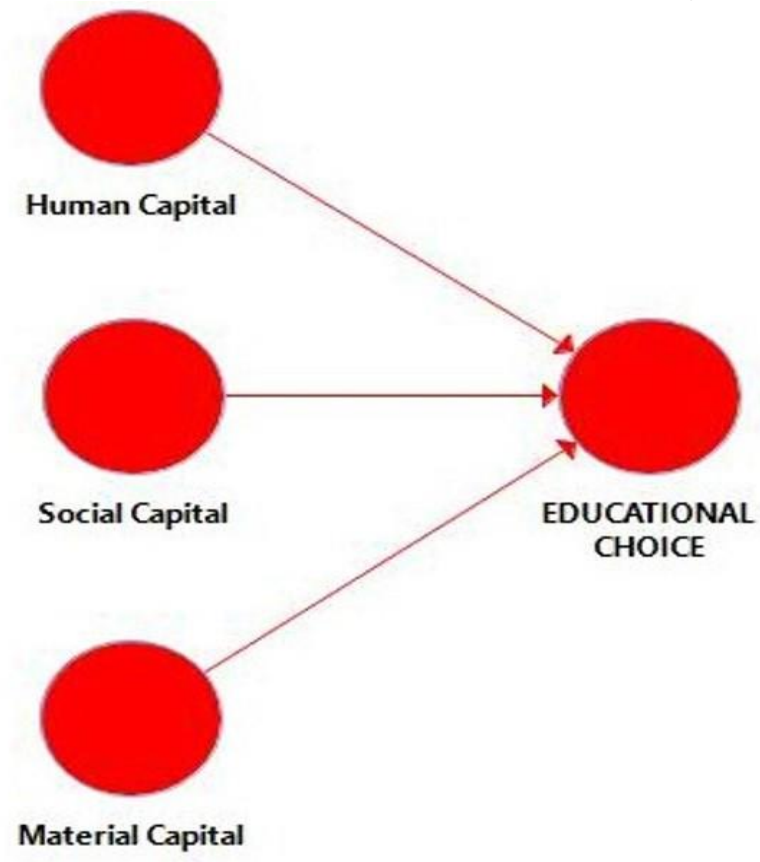

Figure 1 Hypothesised Model

The conceptual framework is based on Oakes and Rossi's(2003) CAPSES model. In the study, educational choice (EC) refers to four streams of educations: English medium education (EED), general education (GED), madrasa education (MED) and vocational education (VED). HC refers to individual competency, knowledge, physical abilities and academic experience/achievement. MC has been defined as the real property (e g. home land), income from earning i.e., wages/salaries, tips and other taxable employee pay/selfemployment, income from investment i.e., interest payments, dividends and capital gains 
collected upon the sale of a security and fungible goods e g. gold, company shares, bonds, other precious metals and currencies. Finally, SC includes social network, trustworthiness, status and power (Oakes and Rossi 2003). The Table 1 clarifies the items of these three exogenous constructs (Human Capital, HC; Social Capital, SC; and Material Capital, MC) as well as one endogenous construct (Educational Choice, EC):

Table 1 Indicators of Exogenous and Endogenous Constructs

\begin{tabular}{|c|l|}
\hline SL & HUMAN CAPITAL FACTORS \\
\hline $\mathbf{1}$ & HC1: Individual Competency \\
\hline $\mathbf{2}$ & HC2: Physical Ability \\
\hline $\mathbf{3}$ & HC3: Knowledge \\
\hline $\mathbf{4}$ & HC4: Academic Achievement \\
\hline & MATERIAL CAPITAL FACTORS \\
\hline $\mathbf{5}$ & MC1: Real Property \\
\hline $\mathbf{6}$ & MC2: Income from Earning to Bear Costs \\
\hline $\mathbf{7}$ & MC3: Income from Investment \\
\hline $\mathbf{8}$ & MC4: Fungible Goods \\
\hline & \\
\hline & SOCIAL CAPITAL FACTORS \\
\hline $\mathbf{9}$ & SC1: Social Network \\
\hline $\mathbf{1 0}$ & SC2: Trustworthiness \\
\hline $\mathbf{1 1}$ & SC3: Status \\
\hline $\mathbf{1 2}$ & SC4: Domination \\
\hline & \\
\hline & ITEMS OF EDUCATIONAL CHOICE \\
\hline $\mathbf{1 3}$ & EED: English Medium Education \\
\hline $\mathbf{1 4}$ & GED: General Education \\
\hline $\mathbf{1 5}$ & MED: Madrasa Education \\
\hline $\mathbf{1 6}$ & VED: Vocational Education \\
\hline & \\
\hline
\end{tabular}

\section{Research Methodology}

\subsection{Research Methods and Instruments}

The study, which is quantitative in nature, employed survey method, using structured questionnaire technique based on 5 point-Likert Scale (e.g., Strongly Disagree=1, Disagree $=2$, Neutral=3, Disagree $=4$ and Strongly Agree=5. The survey consists of 4 sections. The first section covers the respondents' socio-demographics such as gender, age, family size, religion, and ethnicity. The other sections of the questionnaire include Human Capital (HC), Social Capital (SC), Materia Capital (MC) and Educational Choice (EC) in the study areas (Table 1).

\subsection{Sample Size and Sampling Technique}

The study selected 72 parents of Bangladesh as sample from both urban and rural areas using purposive sampling technique.18 EED background parents have been chosen from Gulshan, Banani and Dhanmondi areas (each containing 6 respondents) while the rest 54 parents have been selected from three villages of Kashba Majhail Union: Vatshala, Kashba Majhail and Lakhsmipur, each containing 18 (6 from GED, 6 from MED and another 6 from VED background respondents). The respondents have been selected using purposive sampling 
technique for achieving the purpose of the study. The respondents have been taken from 2 districts considering both affluent and rural areas: Dhaka and Kashba Majhail Union of Pangsha thana under Rajbari district. Three areas of Dhaka city (Gulshan, Banani and Dhanmondi) have been selected, considering as the affluent areas, only for EED background parents. The detail of the distribution of sample size is evident from the Table 2 below.

Table 2 Distribution of the Sample Size

\begin{tabular}{|c|c|c|c|c|c|c|c|}
\hline \multirow{3}{*}{$\begin{array}{c}\text { TYPES OF } \\
\text { RESPONDENTS }\end{array}$} & \multicolumn{6}{|c|}{$\begin{array}{c}\text { PLACE OF } \\
\text { RESPONDENTS }\end{array}$} & \multirow[t]{3}{*}{ TOTAL } \\
\hline & \multicolumn{3}{|c|}{ Urban Areas } & \multicolumn{3}{|c|}{ Rural Areas } & \\
\hline & Gulshan & Banani & $\begin{array}{l}\text { Dhan- } \\
\text { mondi }\end{array}$ & Vatshala & $\begin{array}{c}\text { Kasba } \\
\text { Majhail }\end{array}$ & $\begin{array}{l}\text { Laksmi- } \\
\text { pur }\end{array}$ & \\
\hline $\begin{array}{c}\text { English Medium } \\
\text { Education Background }\end{array}$ & 6 & 6 & 6 & - & - & - & 18 \\
\hline $\begin{array}{c}\text { General Education } \\
\text { Background }\end{array}$ & - & - & - & 6 & 6 & 6 & 18 \\
\hline $\begin{array}{c}\text { Madrasa Education } \\
\text { Background }\end{array}$ & - & - & - & 6 & 6 & 6 & 18 \\
\hline $\begin{array}{c}\text { Vocational Education } \\
\text { Background }\end{array}$ & - & - & - & 6 & 6 & 6 & 18 \\
\hline TOTAL & 6 & 6 & 6 & 18 & 18 & 18 & 72 \\
\hline
\end{tabular}

\subsection{Data Analysis and Instruments}

To analyse both measurement model and the structural model, the study used Smart PLS software. For measurement models, both reliability (Cronbach's alpha, rho, CR and AVE) and validity (e.g., convergent and discriminant) of data have been measured and confirmed. And the structural models have been evaluated through $\mathrm{R}^{2}$ (the explanatory power of the models or coefficient of determination), structural path coefficients, effect size $\left(\mathrm{f}^{2}\right)$, collinearity statistics and $\mathrm{Q}^{2}$ (predictive power and relevance of the exogenous constructs to endogenous construct).

\section{Ethical Consideration}

Confidentiality of the information provided by the respondents was strictly maintained. While interviewing the respondents, force and coercion was also avoided.

\section{Study Findings and Discussion}

\subsection{Characteristics of the Respondents}

Table 3 shows that 61.10 percent of the respondents were above 40 years and the remaining were up to 40 years. With regards to family size, all the respondents have family size upto 4 . In terms of ethnicity and religion, 100 percent respondents were found Bengali and Muslim. Educational backgrounds of the respondents were found to be EED, GED, MED and VED, each containing 25 percent of the total respondents. 
Table 3 Demographic Characteristics

\begin{tabular}{|c|c|c|c|}
\hline \multicolumn{2}{|c|}{ Demographics } & N & \% \\
\hline \multirow{2}{*}{ Age } & Upto 40 Years & 28 & 38.90 \\
\cline { 2 - 4 } & Above 40 Years & 44 & 61.10 \\
\hline \multirow{2}{*}{ Gender } & Female & 20 & 27.80 \\
\cline { 2 - 4 } & Male & 52 & 72.20 \\
\hline \multirow{3}{*}{ Family size } & Upto 4 & 72 & 100.00 \\
\cline { 2 - 4 } & Above 4 & 0 & 0.00 \\
\hline & EED & 18 & 25.00 \\
\cline { 2 - 4 } & GED & 18 & 25.00 \\
\cline { 2 - 4 } Ethnicition & MED & 18 & 25.00 \\
\cline { 2 - 4 } & VED & 18 & 25.00 \\
\hline \multirow{3}{*}{ Religion } & Bengali & 72 & 100.00 \\
\cline { 2 - 4 } & Others & 0 & 0.00 \\
\cline { 2 - 4 } & Muslim & 28 & 38.90 \\
\hline
\end{tabular}

\subsection{Measurement Models}

From the Figure 2, it is evident that there is a positive effect of HC, SC and MC on EED and GED models while the negative effects of those constructs on MED and VED models. Considering the formative nature of educational choice of the respondents, four separate reflective models were constructed to explain the choice of different educational tracks in the study areas (Figure 3, 4, 5 and 6).

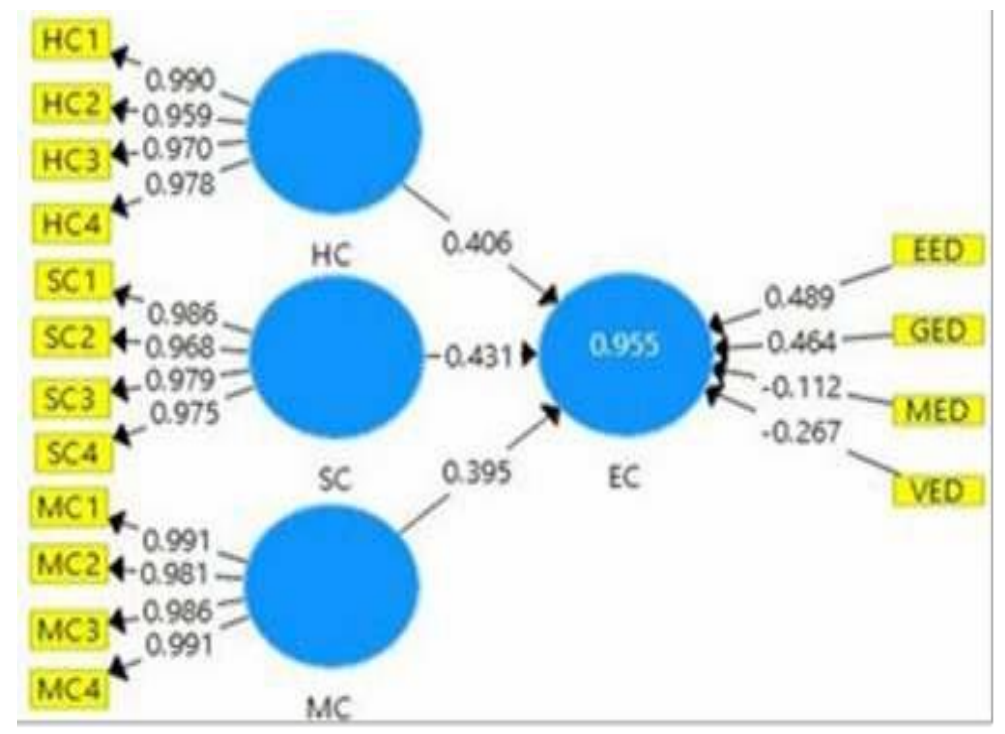

Figure 2 Factor Analysis

The Figure-3, 4, 5 and 6 as well as table 4 show the internal consistency and reliability of data. From Figure 3, it is found that the values of $\mathrm{HC} 1, \mathrm{HC} 2, \mathrm{HC} 3$ and $\mathrm{HC} 4$ are respectively 0.989, 0.960, 0.971 and 0.977; the values of SC1, SC2, SC3 and SC4 are respectively 0.986, 0.969, 0.979 and 0.974; and the values of MC1, MC2, MC3 and MC4 are respectively 0.991, 0.981, 0.986 and 0.991.So, the reliability of data for EED model is confirmed since the values are found to be greater than the threshold value of 0.70 (Wong 2013). Also, the reliability of data is confirmed for all those models considering the composite reliability (CR), rho and Cronbach's Alpha of HC, SC and MC. 


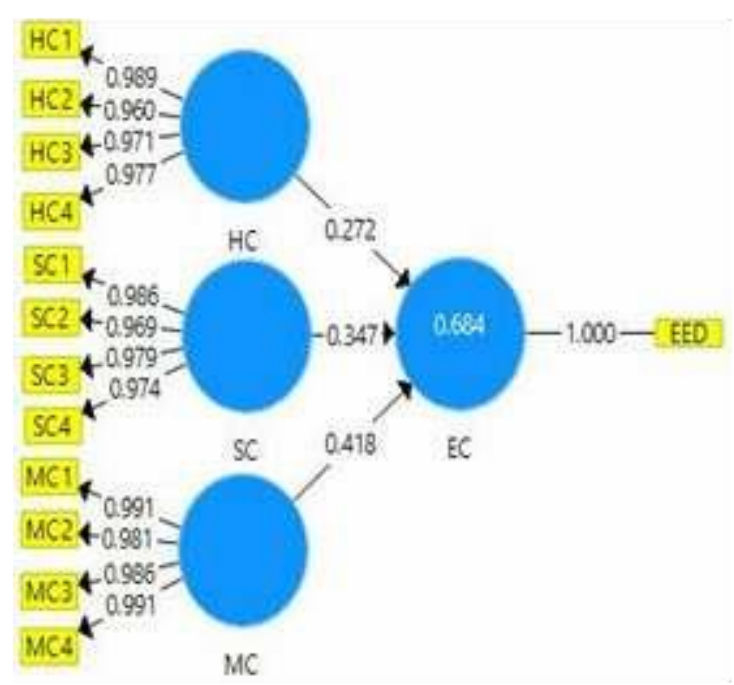

Figure 3 EED Model

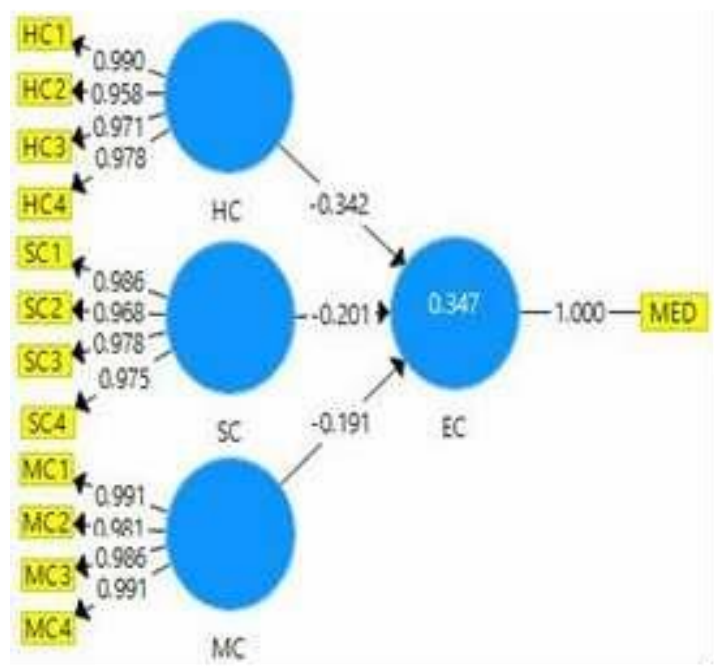

Figure 5 MED Model

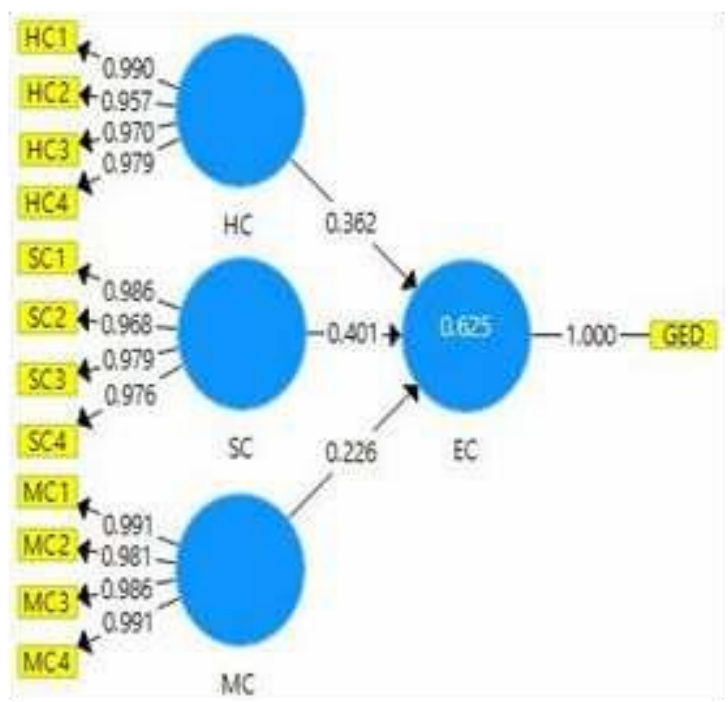

Figure 4 GED Model

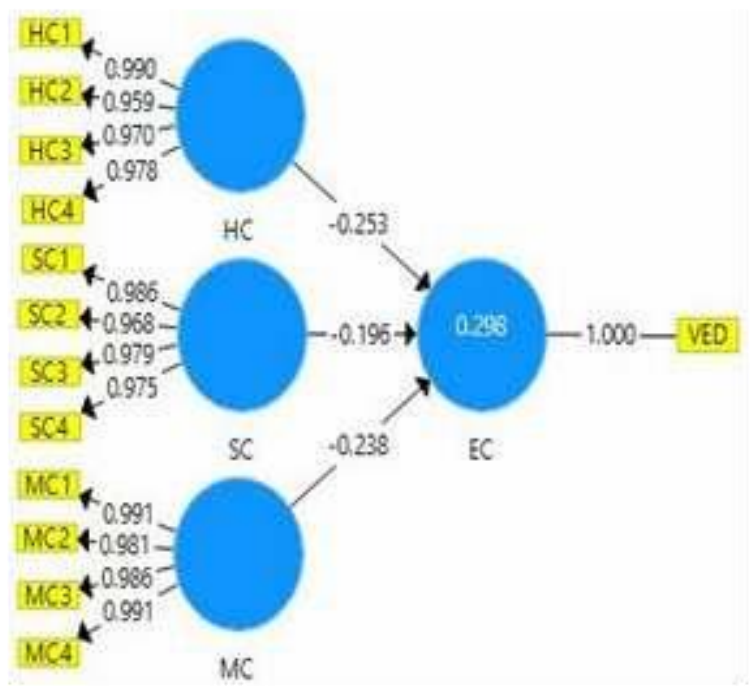

Figure 6 VED Model

Table 4 shows that convergent validitiesfor all those models based on the "Average Variance Extracted' (AVE) values of each latent variable. For EED model, the AVE values ( 0.95 for $\mathrm{HC}, 0.97$ for MC and 0.95 for SC) are found to be greater than the acceptable threshold level of 0.5 (Wong 2013). Similarly, AVE values for GED, MED and VED models are found to be much greater than 0.5 . So, the convergent validity for all the models are confirmed.Table 5 and Table 6 show the discriminant validity of data. From Table 5, we find in all the different rows and columns that the values, which lie in the different starting rows and columns, are greater than other values in that corresponding rows and columns. So, the discriminant validity is confirmed for all the models according to the Fornell-Larcker criterion. Table 6 also confirms the discriminant validity of data for those models since the values based on HTMT ratios are found to be lessthan the threshold value of 0.85 (see Clark and Watson 1995) or 0.90 (see Gold, Malhotra, and Segars 2001). 

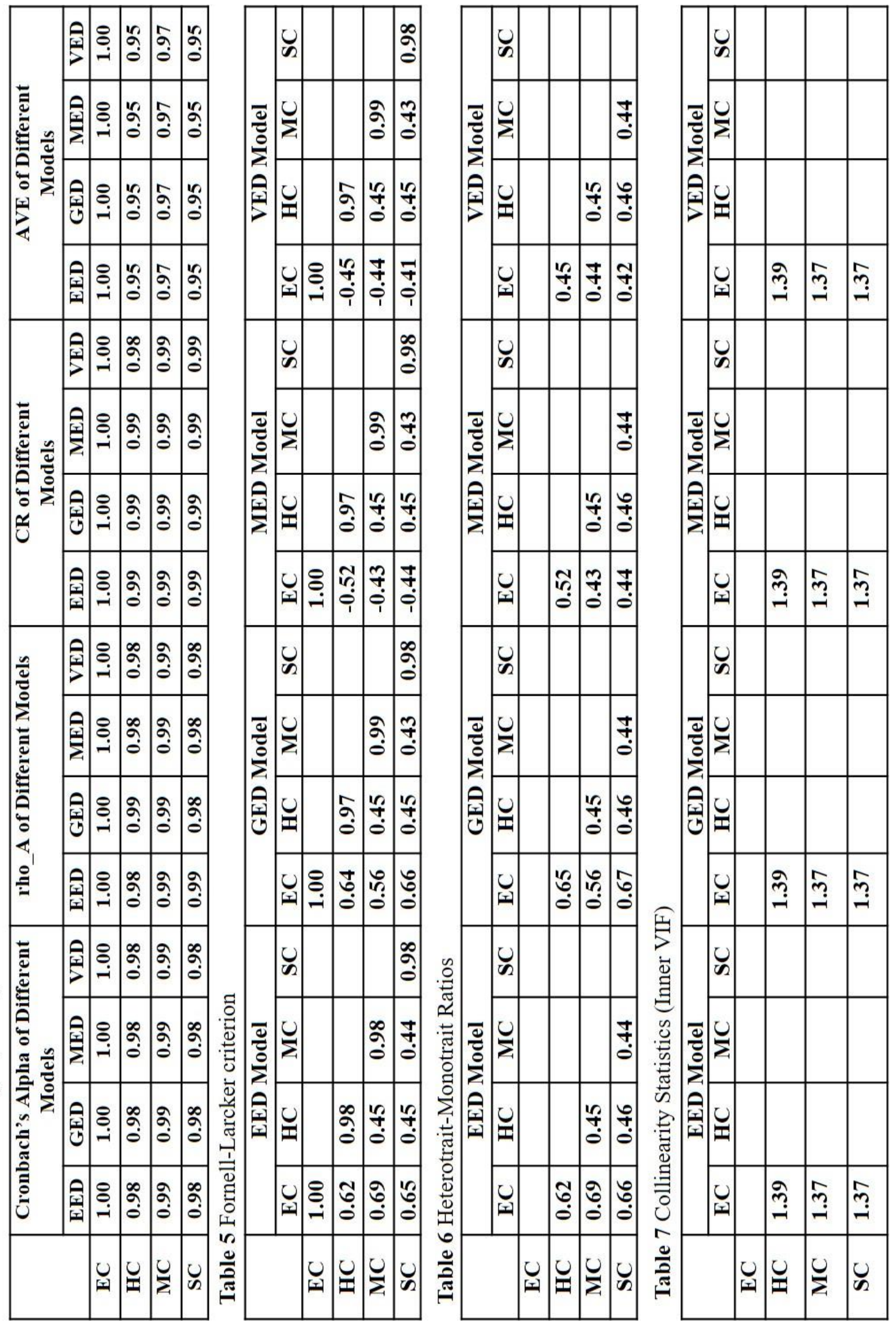

\subsection{Structural Models}

To evaluate structural model, the study considers collinearity assessment, path coefficients, Tstatistics and $\mathrm{P}$ values, coefficients of determination $\left(\mathrm{R}^{2}\right)$, effect size of exogenous constructs 
on endogenous constructs $\left(\mathrm{f}^{2}\right)$, predictive power/relevance of endogenous construct $\left(\mathrm{Q}^{2}\right)$ and predictive contribution of exogenous to endogenous constructs $\left(\mathrm{q}^{2}\right)$. From the Table $7,8,9$ and 10 , we find the statistics for evaluating the four structural models.

First, from Table 7, we find that no values related to variance inflation factor (VIF)are found to be greater than 3. So, the latent variables have no problem of multi-collinearity (see Hair et al. 2010).

Secondly, in terms of path coefficient effect, we find from figure-3, 4, 5 and 6 that all the standardised path relationships such as HC-EC, MC-EC and SC-EC are found to be statistically significant since the standardized path coefficientsare greater than the threshold value of 0.1 (Wong 2013). For EED model, the standardized path relationships between HCEC, MC-EC and SC-EC are respectively $0.272,0.418$ and 0.347. For GED model, the standardized path relationships between HC-EC, MC-EC and SC-EC are respectively 0.362, 0.226 and 0.401 . For MED model, the standardized path relationships between HC-EC, MCEC and SC-EC are respectively $-0.342,-0.191$ and -0.201. And for VED model, the standardized path relationships between HC-EC, MC-EC and SC-EC are respectively -0.253 , -0.238 and -0.196 .

Thirdly, the Table 8 shows structural path significance based on bootstrap method taken the large number of subsamples of 5000. Using a two-tailed t-test at a significance level of 5\%, we find that all the linkages, in the EED, GED and VED models, are found to be statistically significant for all the T-statistics are greater than 1.96 and the $\mathrm{P}$ values are smaller than 0.05 . For EED model, the T-statistics corresponding to the linkages between HC and EC, MC and EC as well as SC and EC are respectively 3.90 (P of 0.000), 5.67 (P of 0.000) and 5.25 (P of 0.000). For GED model, T-statistics corresponding to the linkages between HC and EC, MC and EC as well as SC and EC are respectively 3.99 (P of 0.000), 2.81 (P of 0.005) and $4.45(\mathrm{P}$ of 0.000). For VED model, the T-statistics corresponding to the linkages between HC and EC, MC and EC as well as SC and EC are respectively 2.34 (P of 0.019), 2.28 (P of 0.022) and 2.25 ( $\mathrm{P}$ of 0.025). However, the linkage between $\mathrm{MC}$ and $\mathrm{EC}$ in the MED model ( $\mathrm{T}$ value of $1.922 \& \mathrm{P}$ value 0.055 ) is not found to be statistically significant while other linkages (HC and EC as well as SC and EC) in the MED model is found to be significant since the Tstatistics are respectively ( $T$ value of 3.46 with $P$ value 0.001 and $T$ value of 4.00 with $P$ value $0.045)$.

Fourthly, in terms of coefficient of determination, $\mathrm{R}^{2}$, the endogenous latent variable substantially explains $(68.4 \%)$ the variance in EED model and moderately explain $(62.5 \%)$ the variance in the GED model whereas in cases of two other models, $\mathrm{R}^{2}$ values are not strong $\left(\mathrm{R}^{2}=0.347\right.$ for MED model and $\mathrm{R}^{2}=0.298$ for VED model) (see Wynne W. Chin,2010).

Fifthly, the Table 9 shows that the effect size $\left(\mathrm{f}^{2}\right)$ of the exogenous construct ' $\mathrm{MC}$ ' $(0.40)$ on the endogenous construct ' $\mathrm{EC}$ ' in the EED model is large since the effect size is greater than 0.35 (see Hair et. al., 2010) while the effect sizes of the exogenous constructs ' $H C$ ' $(0.28)$ and 'SC' (0.17)on the endogenous construct ' $\mathrm{EC}$ ' in the EED model is medium. For GED model, the effect sizes of ' $\mathrm{HC}$ ' $(0.25)$ and $\mathrm{SC}(0.31)$ on the ' $\mathrm{EC}$ ' are medium since the effect sizes are greater than 0.15 (see Hair et. al., 2010). On the other hand,the effect sizes of the all the exogenous constructs-' $\mathrm{HC}$ ' $(0.13)$, ' $\mathrm{MC}$ ' $(0.04)$ and ' $\mathrm{SC}^{\prime}(0.04)-$ on the 'EC' in the MED model and those of ' $\mathrm{HC}$ ' $(0.06)$, 'MC' $(0.06)$ and ' $\mathrm{SC}$ ' $(0.04)$ on the 'EC' in the VED model are small since the effect sizes are less than 0.15 (see Hair et. al., 2010). 


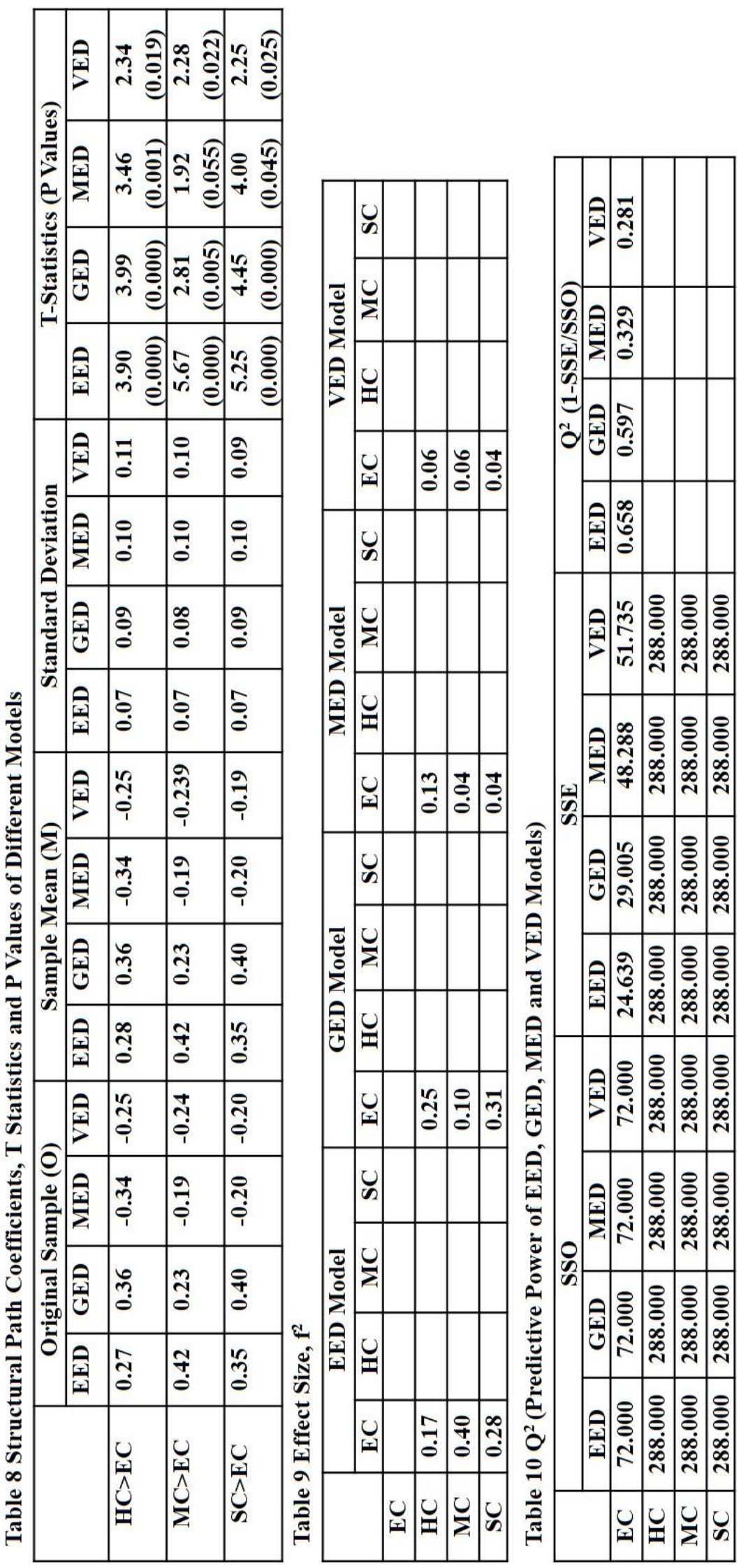


Sixthly, along with evaluating the magnitude of $\mathrm{R}^{2}$ values as criterion of predictive accuracy, the study has also examined Stone-Geisser's $Q^{2}$ value (Geisser 1975; Stone 1974). That is, to measure the model's predictive power or predictive relevance of endogenous construct 'EC', the value of $\mathrm{Q}^{2}$ has been calculated using Blindfolding method. The Table 10 shows the strong predictive power and relevance of endogenous constructs ' $E C$ ' in all the models since the $\mathrm{Q}^{2}$ values (0.658 for EED model, 0.597 for GED model, 0.329 for MED model and 0.281 for VED model) are much greater than the threshold value of 0 (Geisser 1975; Stone 1974).

\section{Conclusion and Recommendations}

The study explains the educational choice of children in Bangladesh based on the CAPSES model. After PLS-SEM analysis of empirical data, the study finds significant effects of human capital, material capital and social capital on the parents' choice of their children's educational track in Bangladesh. In terms of the structural path significance ' $T$ ' test based on bootstrap method taken the large number of subsamples of 5000, only the relationship between ' $\mathrm{MC}$ ' and 'EC' in the MED model was not found to be statistically significant while the relationships among all other linkages in all the models were found to be statistically significant since the T-statistics were found to be greater than 1.96 and P-values were less than 0.05. Thus, the study findings lead to this proposition that the higher the magnitude of socioeconomic status the parents hold to, the higher the likelihood ratio that they will choose the English medium education for their children and the vice-versa. On the contrary, the lower the magnitude of socioeconomic status the parents hold to, the higher the likelihood ratio that they will choose the madrasa or vocational track of education for their children and viceversa. Overall, the models have predictive power and relevance ( $R 2=0.684$ for EED model, $\mathrm{R} 2=0.625$ for GED model, $\mathrm{R} 2=0.347$ for MED model and $\mathrm{R} 2=0.298$ for VED model). However, the study as an underexplained phenomenon has some recommendations for future researchers. First, the future researchers should conduct rigorous research works using probability sampling technique to make the findings more representative. Finally, sociologists of Bangladesh should contribute to the pitch of 'Sociology of Education' moving from the CAPSES model of the educational choice of children in Bangladesh. 


\section{References}

Blau, P. M., \& Duncan, O. D. (1967). The American Occupational Structure. New York: Wiley.

Bourdieu, P. (1977). Cultural reproduction and social reproduction. In: Karabel, J. and Halsey, A. H., eds. Power and Ideology in Education. New York: Oxford University Press. 487-511.

Bowles, S., \& Gintis, H. (2011). Schooling in capitalist America: Educational reform and the contradictions of economic life. Haymarket Books.

Breen, Richard, and Jonsson, Jan O. (2000). 'Analysing Educational Careers: A Multinomial Transition Model'. American Sociological Review 65 (5): 754-72.

Callender, C., and Jackson, J. (2004). Fear of Debt and Higher Education Participation. Families and Social Capital ESRC Research Group. Working Paper No. 9. London: London South Bank University.

Carneiro, P., Hansen, K. T., \& Heckman, J. J. (2003). Estimating Distributions of Treatment Effects with an Application to the Returns to Schooling and Measurement of the Effects of Uncertainty on College (No. w9546). National Bureau of Economic Research.

Chin, W. W. (2010). 'How to Write Up and Report PLS Analyses'. In Handbook of Partial Least Squares: Concepts, Methods and Applications, edited by V. Esposito Vinzi, Wynne W. Chin, J. Henseler, and H. Wang, 655-90. Berlin, Heidelberg: Springer Berlin Heidelberg.

Clark, Lee Anna, and Watson, David. (1995). 'Constructing Validity: Basic Issues in Objective Scale Development'. Psychological Assessment 7 (3): 309-19.

Coons, J. E., \& Sugarman, S. D. (1978). Education by choice: The case for family control. Univ of California Press.

Davies, Scott, and Guppy, Neil. (1997). 'Fields of Study, College Selectivity, and Student Inequalities in Higher Education'. Social Forces 75 (4): 1417-38.

Geisser, S. (1975). 'A Predictive Approach to the Random Effect Model'. Biometrika 61 (1): $101-7$.

Gold, A. H., Malhotra, A., \& Segars, A. H. (2001). Knowledge management: An organizational capabilities perspective. Journal of management information systems, $18(1), 185-214$.

Hair, Joseph F., William C. Black, Barry J. Babin, and Rolph E. Anderson (2010), Multivariate Data Analysis, Englewood Cliffs, NJ: Prentice Hall.

Jackson, G. (1990). 'Financial Aid, College Entry, and Affirmative Action'. American Journal of Education 98 (4): 523-550.

Jaeger, Mads Meier. (2009). 'Equal Access but Unequal Outcomes: Cultural Capital and Educational Choice in a Meritocratic Society'. Social Forces 87 (7): 1943-71. http://socialforces.unc.edu/epub/folder.2007-02-09.8541500563/june09.

Jonsson, J. O., Grusky, D. B., Di Carlo, M., Pollak, R., \& Brinton, M. C. (2009). Microclass mobility: Social reproduction in four countries. American Journal of Sociology, 114(4), 977-1036.

Kingdon, G., and Cassen, R. (2007). Understanding Low Achievement in English Schools, 118.

Lata, L. N. (2013). Cultural capital and higher education in Bangladesh. International Review of Modern Sociology, 225-238.

Lauder, H., Hughes, D., Watson, S., Waslander, S., \& Strathdee, M. (1999).Trading in 
Futures: Why Markets in Education Don't Work. Philadelphia: Open University Press.

Lyons, Maureen. (2003). Inside Classrooms: The Teaching and Learning of Mathematics in Social Context. Dublin: Institute of Public Administration.

Oakes, J. M., \& Rossi, P. H. (2003). The measurement of SES in health research: current practice and steps toward a new approach. Social science \& medicine, 56(4), 769-784.

Smith, Teresa, and Noble, Michael. (1995). Education Divides: Poverty and Schooling in the 1990s. Oxford: Child Poverty Action Group.

Stone, M. (1974). 'Cross-Validatory Choice and Assessment of Statistical Predictions'. Journal of the Royal Statistical Society. Series B (Methodological) 36 (2): 111-47.

Wong, Ken Kwong-Kay. (2013). 'Partial Least Square Structural Equation Modeling (PLSSEM) Techniques Using SmartPLS'. Marketing Bulletin 24: 1-32. 